\title{
Glycolaldehyde dimer in the stable crystal phase has axial OH groups: Raman, infrared and X-ray data analysis
}

Vlasta Mohaček-Grošev*a, Biserka Prugovečki ${ }^{\mathrm{b}}$, Stjepan Prugovečki ${ }^{\mathrm{c}}$, Neven $^{\mathrm{a}}$ Strukan $^{\mathrm{d}}$

\section{Graphical abstract}
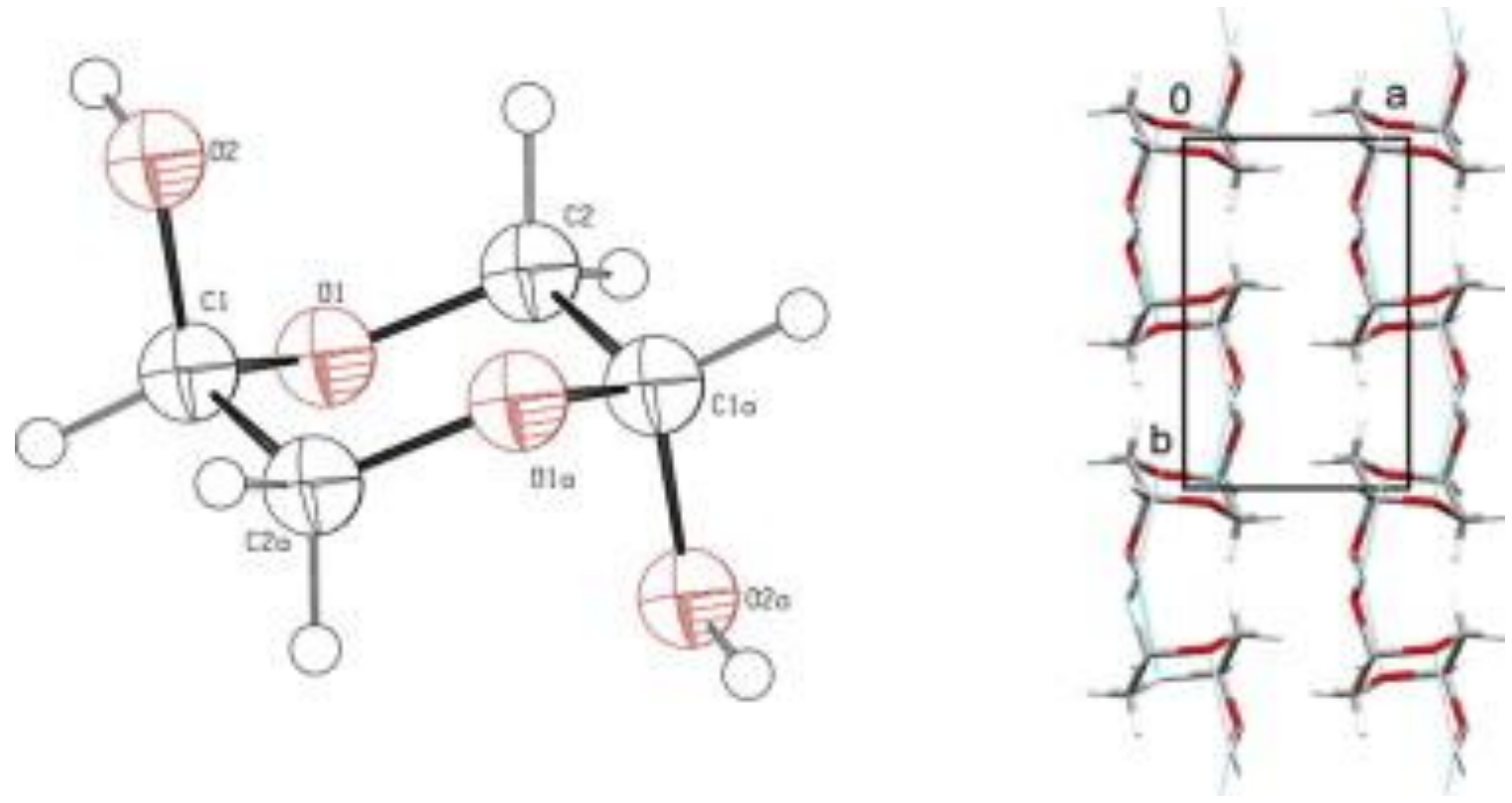

Abstract

Although a small molecule and a simple 1,4-dioxane derivative, 2,5-dihydroxy-1,4-dioxane or glycolaldehyde dimer has a crystal structure that has eluded researchers so far, chief reason lying presumably in substance polymorphism. Here we report for the first time on the stable crystal structure of the glycolaldehyde dimer characterized by the X-ray powder diffraction method at room temperature. It crystallizes in the monoclinic system, space group $P 2_{1} / c$, with unit cell parameters $a=5.9473(1) \AA, b=8.3997(1) \AA, c=5.61953(8) \AA$ and $\beta=114.8814(9)^{\circ}$. The glycolaldehyde dimer molecules are the trans-isomers with the electronegative hydroxyl groups in axial positions and molecules are arranged in hydrogen bonded layers parallel to $\left(\begin{array}{lll}1 & 0 & 0\end{array}\right)$. Each layer is stabilized by intermolecular medium strong $\mathrm{O}-\mathrm{H} \cdots \mathrm{O}$ hydrogen bonds. The 1,4-dioxane ring of the molecule adopts a chair conformation.

\footnotetext{
${ }^{a}$ Ruđer Bošković Institute, POB 180, Bijenička cesta 54, 10002 Zagreb, Croatia (mohacek@irb.hr)

${ }^{b}$ Department of Chemistry, Faculty of Science, University of Zagreb, Horvatovac 102a, 10000 Zagreb, Croatia (biserka@chem.pmf.hr)

c PANalytical B.V., Twentepoort Oost 26, 7609 RG Almelo, The Netherlands

${ }^{d}$ Renacon d.o.o., Vrbik 20, 10000 Zagreb, Croatia
} 
Raman and infrared spectra were re-examined and assigned with the help of $a b$ initio calculation followed by a normal modes analysis modes most sensitive to crystal packing were identified as the $\mathrm{C}-\mathrm{OH}$ deformations which were assigned to the IR and Raman bands at 1239 and $1237 \mathrm{~cm}^{-1}$, respectively; the two O-C-O deformation modes, both associated with the Raman and IR bands at 561 and $535 \mathrm{~cm}^{-1}$ and, the two $\mathrm{OH}$ torsion modes assigned to the IR bands at 630 and $604 \mathrm{~cm}^{-1}$.

\section{Keywords}

Glycolaldehyde; Crystal structure; X-ray diffraction; Raman; Infrared

\section{Introduction}

Glycolaldehyde is the simplest sugar - related molecule containing both an aldehyde and a hydroxyl group, $\mathrm{CHOCH}_{2} \mathrm{OH}$. The fact that it is the first sacharide found in the interstellar space [1] and the role it plays in the energy metabolism in humans [2], has motivated microwave [3] and conformational studies [4], [5], [6] and [7], electron beam radiation experiments [8], as well as infrared spectroscopic studies of molecules isolated in noble gases [9] or parahydrogen matrix [10]. In the solid state, pure glycolaldehyde exists in the form of a dimer [11] and [12]. Previous vibrational studies on solid glycolaldehyde were done by Michelsen and Klaboe [13] who compared infrared and Raman spectra of solid with the infrared spectrum of vapor, confirming centrosymmetric structure of the dimer as completely different from the monomer structure present in the vapor. Kobayashi et al. [14] succeeded in obtaining two crystalline forms $\alpha$ and $\beta$ of glycolaldehyde and compared their infrared and Raman spectra, including the far infrared region. They claimed that in the $\alpha$ form the hydroxyl groups are placed in equatorial position on the 1,4-dioxane ring, while in the $\beta$ form axial position of the $\mathrm{OH}$ groups was more probable. Mohaček-Grošev used low temperature Raman spectroscopy to probe the $\alpha$ structure, and performed semi-empirical normal coordinate analysis of the dimer both with equatorial and with axial hydroxyl groups [15] in order to establish the dimer conformation. Doubling of the number of the phonon bands below $80 \mathrm{~K}$ indicated that the $\alpha$ phase might be transformed into the third, $\gamma$ phase. Her conclusion that a dimer with equatorial groups is present in the stable phase was based on the expectation of $150 \mathrm{~cm}^{-1}$ Raman mode for an axial conformer, which was not observed.

Here we report on the crystal structure of 2,5-dihydroxy-1,4-dioxane (glycolaldehyde dimer) characterized by the X-ray powder diffraction method. Infrared and Raman spectra were reexamined and reassigned, this time using ab initio method of calculation, accompanied with potential energy distribution. 


\section{Experimental}

Glycolaldehyde, purity greater than $98 \%$, was purchased from Fluka and sealed in a capillary tube. Raman and infrared experiments were performed at room temperature as described in [15].

\subsection{Powder diffraction}

The powder diffraction data for glycolaldehyde dimer were collected on a laboratory PANalyticalX'Pert Pro diffractometer in the capillary transmission geometry mode with focusing mirror and $\mathrm{X}^{\prime}$ Celerator detector, using $\mathrm{Cu} \mathrm{K} \alpha$ radiation. The sample was contained in a $0.5 \mathrm{~mm}$ glass capillary. Patterns were collected from $12^{\circ}$ to $80^{\circ}(2 \theta)$ with a step size of $0.0084^{\circ}$. The total data collection time was $5 \mathrm{~h}$ and $40 \mathrm{~min}$. The powder pattern was indexed on first 15 peaks by the DICVOL04 program [16] integrated into the HighScore Plus program [17]. The initial cell parameters were obtained with the figure of merit $M(15)=191$. One peak at $17.8^{\circ}(2 \theta)$ with the relative intensity of $1.2 \%$ remained unindexed, indicating a low level polymorphic or chemical impurity and was excluded from the unit cell refinement. The unit cell parameters were refined by the least squares fit implemented in the HighScore Plus program. The refined unit cell parameters are $a=5.9473(1) \AA, b=8.3997(1) \AA, c=5.61953(8) \AA$ and $\beta=114.8814(9)^{\circ}$. Space group search was made by trying the Le Bail full profile fitting [18] for all monoclinic space groups. The comparison of fitting residue values and goodness of fit suggested space group $P 2_{1} / c$ as the most probable one. The structure was solved in the space group $P 2_{1} / c$ by direct methods, using the EXPO2009 [19] program. Structure refinement was carried out by the Rietveld [20] refinement program implemented in the HighScore Plus. The peak profiles were refined by the Pseudo-Voigt profile function (modified by the asymmetry correction of Finger, Cox and Jephcoat [21]). The background was modeled by the Chebychev-I function. The fractional atomic coordinates and isotropic thermal parameters for all non-H atoms were refined without any constraints. The final fit of the model to the experimental data and a difference plot are given in Fig. S1. The residual of the final fit were: $R_{\mathrm{p}}=0.052$ and $R_{\mathrm{wp}}=0.074$. The crystallographic data are summarized in Table 1

Table 1 Crystallographic data for glycolaldehyde dimer.

\begin{tabular}{|c|l|}
\hline \multicolumn{2}{|c|}{} \\
\hline Chemical formula & $\mathrm{C}_{4} \mathrm{H}_{8} \mathrm{O}_{4}$ \\
\hline \multicolumn{1}{|c|}{$M_{\mathrm{r}}$} & 60.05 \\
\hline Powder color & White \\
\hline
\end{tabular}


Mohaček-Grošev, V., Prugovečki, B., Prugovečki, S., Strukan, N. (2013), "Glycolaldehyde dimer in the stable crystal phase has axial OH groups: Raman, infrared and X-ray data analysis", Journal of Molecular Structure, Vol. 1047, pp. 209-215.

\begin{tabular}{|c|c|}
\hline Crystal system & Monoclinic \\
\hline Space group & $P 2_{1} / c$ \\
\hline \multicolumn{2}{|l|}{ Unit cell parameters } \\
\hline$a(\AA)$ & $5.9473(1)$ \\
\hline$b(\AA)$ & $8.3997(1)$ \\
\hline$c(\AA)$ & $5.61953(8)$ \\
\hline$\alpha\left(^{\circ}\right)$ & 90 \\
\hline$\beta\left(^{\circ}\right)$ & $114.8814(9)$ \\
\hline$\gamma\left({ }^{\circ}\right)$ & 90 \\
\hline$V\left(\AA^{3}\right)$ & 254.27 \\
\hline$Z$ & 2 \\
\hline$D_{\text {calc }}\left(\mathrm{g} \mathrm{cm}^{-3}\right)$ & 1.566 \\
\hline Temperature $(\mathrm{K})$ & 293 \\
\hline Wavelength $(\AA)$ & 1.540598 \\
\hline$R_{\mathrm{p}}$ & 0.052 \\
\hline$R_{\mathrm{wp}}$ & 0.074 \\
\hline$R_{\exp }$ & 0.028 \\
\hline Goodness of fit & 6.95 \\
\hline Starting angle $\left({ }^{\circ}, 2 \theta\right)$ & 12 \\
\hline Final angle $\left({ }^{\circ}, 2 \theta\right)$ & 80 \\
\hline Step width $\left({ }^{\circ}, 2 \theta\right)$ & 0.0084 \\
\hline Time/scan & $5 \mathrm{~h} 40 \mathrm{~min}$ \\
\hline
\end{tabular}




\section{Computional details}

Vibrations were calculated with the Gaussian 03 program [22]. The geometry of the dimer was optimized by using the hybrid B3LYP functional with the $6-31++G(d, p)$ basis set. Practically all calculated normal modes except the $441 \mathrm{~cm}^{-1}$ mode can be classified according to the group $\mathbf{C}_{\mathbf{i}}$, either as transforming according to $A_{g}$ or $A_{u}$ irreducible representation. Optimized geometrical parameters are listed and compared to the X-ray data in Table S1 of the Supplementary material. For the normal coordinate calculations, the BALGA program was used [23] and [24]. Definition of internal coordinates is given in Table S2, while local symmetry coordinates are listed in Table S3 of the Supplementary material. Finally, a detailed potential energy distribution is presented in Table S4.

\section{Results and discussion}

Glycolaldehyde in the melt is a rich mixture of monomers, open and closed dimers, some of which include hydroxyl groups simultaneously present in axial and equatorial position in the same molecule [25]. Therefore, determination of the relative stability of two glycolaldehyde dimer forms, one having two hydroxyl groups placed axially, and the other having two $\mathrm{OH}$ groups placed equatorially, is not possible in the way it was performed, e.g. in vibrational studies of bicyclopropyl [26] or cyclobutanol [27].

Observed Raman and infrared spectra of different glycolaldehyde phases were compared to those of dioxane and glyceraldehyde in previous vibrational studies [13], [14] and [15]. Kobayashi et al. [14] were the first to report the existence of a second crystal phase of glycolaldehyde at room temperature and called it the $\beta$ phase. Mohaček-Grošev studied low temperature Raman spectra and found spectral evidence of a new phase $\gamma$ existing below $80 \mathrm{~K}$, which is not present at room temperature [15]. Vibrational spectra of $\alpha$ and $\beta$ phase are rather similar, displaying differences in bands attributed to the $\mathrm{C}-\mathrm{OH}$ group. Those associated to the $\mathrm{C}-\mathrm{OH}$ bending occur in 1200 $1260 \mathrm{~cm}^{-1}$ interval in Raman spectrum, and in $1430-1470 \mathrm{~cm}^{-1}$ interval in infrared spectrum. Most pronounced changes involve the band from infrared spectrum corresponding to the torsion of the hydroxyl group, which is observed at $605 \mathrm{~cm}^{-1}$ in the spectrum of the $\alpha$ phase and at $686 \mathrm{~cm}^{-1}$ in the spectrum of the $\beta$ phase [14].

Kobayashi et al. suggested that the glycolaldehyde dimer possessed two OH groups placed in the equatorial position in the $\alpha$ phase, whereas they might be in the axial position in the $\beta$ phase [14]. This was a reasonable hypothesis, since the equatorial conformation of a hydroxyl group often predominates over the axial one in flexible ring compounds such as cyclobutanol [27] or cyclohexanol [28]. Solidification brought about by cooling or pressurizing, may or may not be accompanied by the change of molecular conformation. For example, the hydroxyl group of cyclobutanol is in the equatorial position at $105 \mathrm{~K}$ [29], while that of cyclopentanol at $1.5 \mathrm{GPa}$ is 
in the axial position [30]. For cyclohexanol, the Hartree-Fock estimate of the energy difference between axial and equatorial conformer depends on the basis set used and varies between 0.19 and $0.86 \mathrm{kcal} / \mathrm{mol}$ [28], equatorial one being more stable. Hydrogen bonding interactions in the solid add further to the complexity of crystal polymorphism [31]. Dabbagh et al. discussed anomeric effect in substituted dioxanes, including 2-hydroxy-1,4-dioxane [32]. The equatorial conformer was predicted to be $0.56 \mathrm{kcal} / \mathrm{mol}$ more stable than the axial at the Hartree-Fock level of theory, while the axial one was more stable than the equatorial by $0.46 \mathrm{kcal} / \mathrm{mol}$ at the B3LYP level or by $0.85 \mathrm{kcal} / \mathrm{mol}$ at the MP2 level of theory (all with the $6-31 \mathrm{G}^{*}$ basis set) [32]. Our results on the glycolaldehyde dimer at the B3LYP/6-31++G(d,p) level of theory gave a similar prediction in favor of the stability of the dimer with two axially positioned hydroxyl groups.

\subsection{X-ray crystallography}

Commercial glycolaldehyde (Fluka) crystallizes as a dimer with a 1,4-dioxane ring in the chair conformation. The puckering parameters of Cremer and Pople [33] for this ring are

$Q=0.477(3) \AA, \Theta=0.00(1)^{\circ}$ and $\varphi=0.00^{\circ}$. The same chair conformation of the 1,4-dioxane ring was found in the trans-isomers of 2,5-dietoxy-2,5-bis(hydroxymethyl)-[1,4]-dioxane [34], in the three crystalline forms of the 2,5-bis(hydroxymethyl)-[1,4]-dioxane-2,5-diol [35], in 2,3,5,6tetramethyl-[1,4]-dioxane-2,5-diol [36], 2,5-dihydroxy-3,6-dihydroxymethyl-[1,4]-dioxane [37] and trans-2,5-di-tert-butoxy-[1,4]-dioxane [38].

The molecular structure of glycolaldehyde dimer is shown in Fig. 1 and selected crystallographic data are given in Table 1. The glycolaldehyde dimer molecules lie on crystallographic centers of symmetry. The Cambridge Structural DataBase, CSDB [39] search using the ConQuest Version 1.14, gave four structures containing the 1,4-dioxane-2,5-diol unit (trans-isomers). The values of bond distance in the glycolaldehyde dimer are similar to those found in CSDB search [34], [35], [36], [37] and [38]. 
Mohaček-Grošev, V., Prugovečki, B., Prugovečki, S., Strukan, N. (2013), "Glycolaldehyde dimer in the stable crystal phase has axial OH groups: Raman, infrared and X-ray data analysis", Journal of Molecular Structure, Vol. 1047, pp. 209-215.

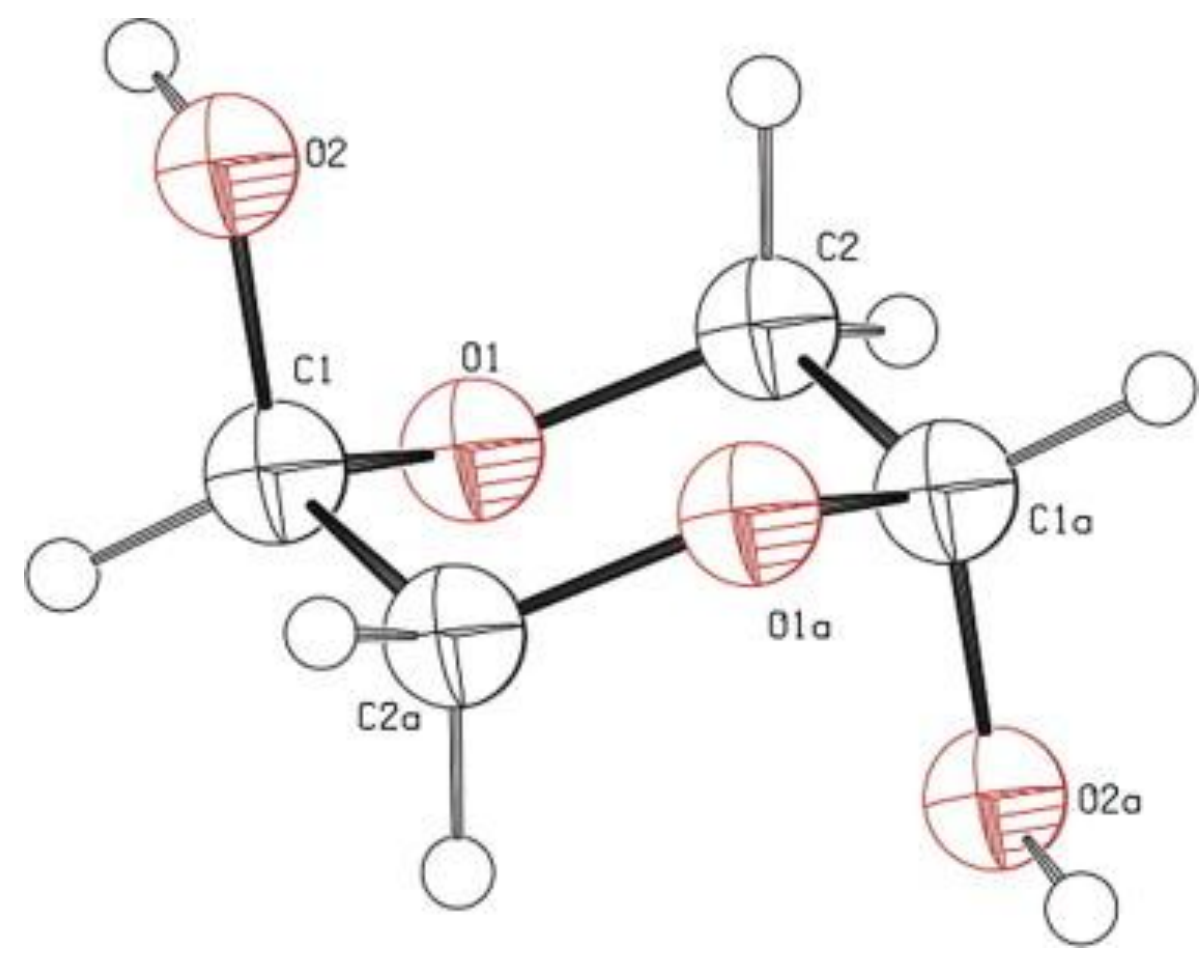

Fig 1 The molecular structure of glycolaldehyde dimer molecule. Displacement ellipsoids are shown at $50 \%$ probability level.

The glycolaldehyde dimer molecules are the trans-isomers with the electronegative hydroxyl groups in axial positions and molecules are arranged in hydrogen bonded layers parallel to $\left(\begin{array}{lll}1 & 0 & 0\end{array}\right)$ (Fig. 2a). Each layer is stabilized by intermolecular hydrogen bonds $\mathrm{O} 2-\mathrm{H} \cdots \mathrm{O} 2[x$,

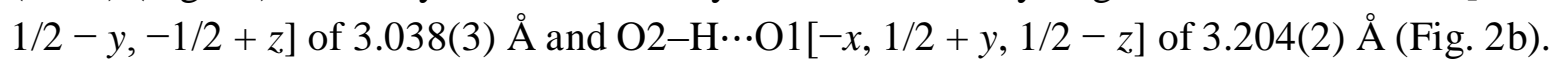
Additionally there are intermolecular hydrogen interactions $\mathrm{C} 1-\mathrm{H} \cdots \mathrm{O} 1$ that stabilize layers. 
Mohaček-Grošev, V., Prugovečki, B., Prugovečki, S., Strukan, N. (2013), "Glycolaldehyde dimer in the stable crystal phase has axial OH groups: Raman, infrared and X-ray data analysis", Journal of Molecular Structure, Vol. 1047, pp. 209-215.

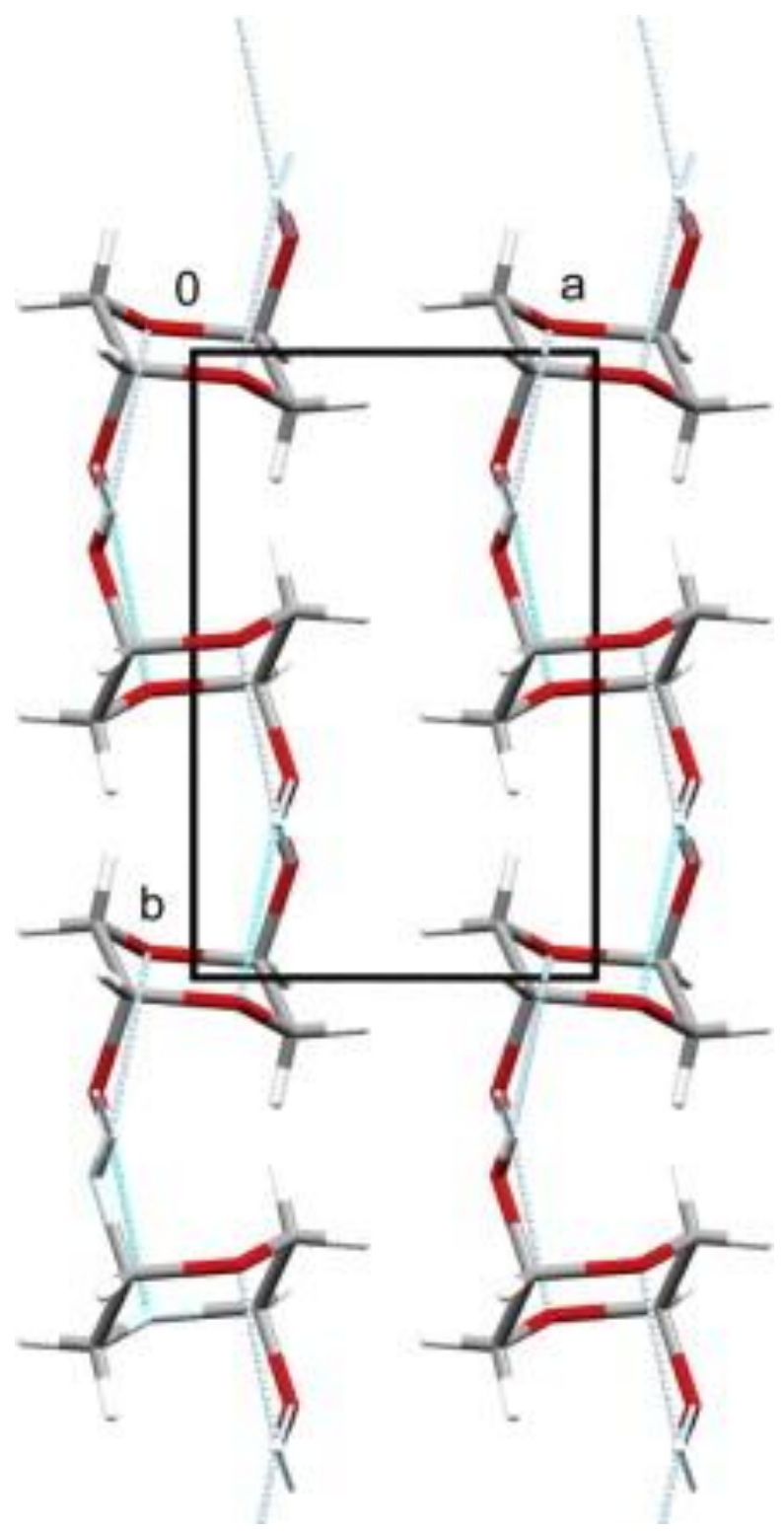

Fig 2a. Packing arrangement of glycolaldehyde dimer molecules displayed in the unit cell viewed along $c$-axis. 


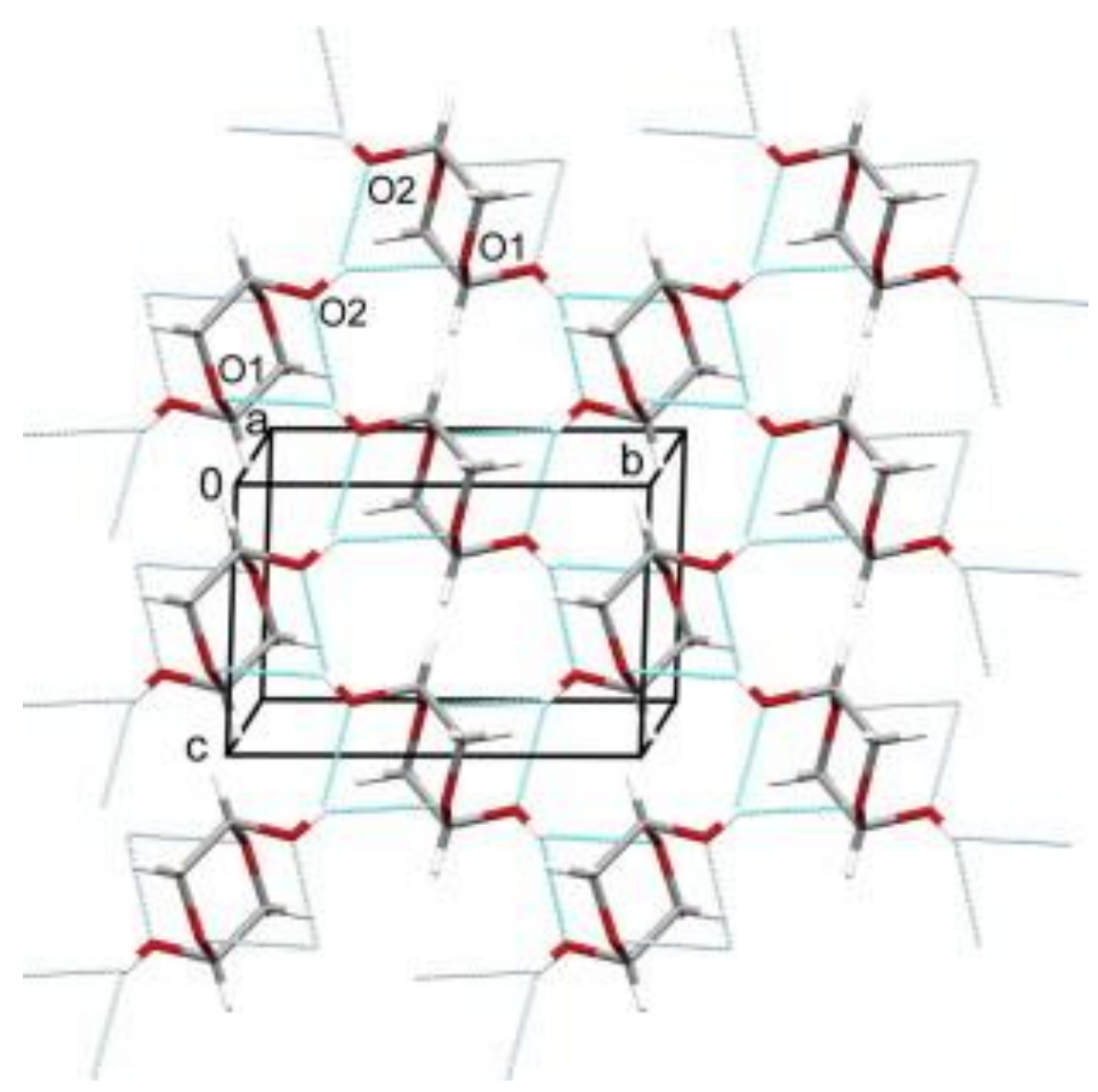

Fig 2b. One selected layer. Intermolecular hydrogen bonds $\mathrm{O} 2-\mathrm{H} \cdots \mathrm{O} 2[x, 1 / 2-y,-1 / 2+z]$ of 3.038(3) $\AA$ and $\mathrm{O} 2-$ $\mathrm{H} \cdot \mathrm{O} \mathrm{O} 1[-x, 1 / 2+y, 1 / 2-z]$ of $\mathbf{3 . 2 0 4}(2) \AA$ are denoted by thin blue lines. (For interpretation of the references to color in this figure legend, the reader is referred to the web version of this article.)

\subsection{Vibrational Spectra}

Two hydrogen bonds are present in the crystal structure of glycolaldehyde dimer: the first is formed by two neighboring hydroxyl oxygen atoms (3.038 $\AA$ apart), and the second one by a hydroxyl oxygen and a ring oxygen atom (3.204 $\AA$ apart). According to Jeffrey [40] they are of medium strength, the shorter the distance between oxygens the stronger the hydrogen bond.

Overall there are ninety-six possible modes, which are divided among the irreducible representation of the $\mathbf{C}_{\mathbf{2 h}}$ point group as:

\section{$\Gamma=24 \mathrm{Ag}+24 \mathrm{~B}_{\mathrm{g}}+24 \mathrm{Au}+24 \mathrm{~B}_{\mathrm{u}}$}

Among these, there are six Raman active $\left(2 \mathrm{~A}_{\mathrm{g}}+4 \mathrm{~B}_{\mathrm{g}}\right)$ and three infrared active external phonons $\left(2 A_{u}+B_{u}\right)$. This leaves forty-two Raman active $(g)$ and forty-two infrared active $(u)$ internal vibrations: 
Mohaček-Grošev, V., Prugovečki, B., Prugovečki, S., Strukan, N. (2013), "Glycolaldehyde dimer in the stable crystal phase has axial OH groups: Raman, infrared and X-ray data analysis", Journal of Molecular Structure, Vol. 1047, pp. 209-215.

\section{$\Gamma_{\text {vib }}=22 A g+20 B g+22 A u+20 B u$.}

Twenty-six bands in Raman and twenty-nine bands in infrared spectrum are observed, much less than the expected number of forty-two. Crystal splitting is not resolved in the case of fifteen modes in Raman spectrum, and for thirteen modes in the infrared spectrum.

One dimer having the symmetry of the point group $\mathbf{C}_{\mathbf{i}}$ would have $21 \mathrm{~A}_{\mathrm{g}}$ Raman active and $21 \mathrm{~A}_{\mathrm{u}}$ infrared active normal modes and we use these modes to assign the vibrational transitions. A comparison of the observed Raman and infrared band positions with calculated unscaled normal modes of a single dimer is made in Table 2. Detailed potential energy distribution is given in Table S4 of the Supplementary material. In general all symmetrical modes exhibit a strong Raman and weak infrared activity, while asymmetrical modes exibit strong infrared and weak Raman activity. The very broad infrared band centered at $3414 \mathrm{~cm}^{-1}$ is assigned to the asymmetrical $\mathrm{OH}$ stretching vibration. Its symmetrical counterpart appears as a weak band in the Raman spectrum at $3417 \mathrm{~cm}^{-1}$ (see Fig. 3). The Raman and IR bands at 2974 and $2973 \mathrm{~cm}^{-1}$ are assigned respectively to $\mathrm{CH}$ stretching vibrations, while the pairs of Raman bands at 3002 and $2956 \mathrm{~cm}^{-1}$ and at 3001 and $2951 \mathrm{~cm}^{-1}$ in the infrared spectrum are associated with $\mathrm{CH}_{2}$ stretching modes. The group of bands observed in the $1250-1460 \mathrm{~cm}^{-1}$ region are associated with $\mathrm{HCC}$ and $\mathrm{HCO}$ deformation modes. To the $\mathrm{COH}$ bending modes a strong infrared band at $1270 \mathrm{~cm}^{-1}$ (see Fig. 4) and a weak Raman band at $1237 \mathrm{~cm}^{-1}$ are assigned, contrasting previous assignment of Kobayashi et al. [14] who attributed it to the $1438 \mathrm{~cm}^{-1}$ infrared band. Stretching deformation of the $\mathrm{C}-\mathrm{C}$ bond contributes in two normal modes corresponding to 1138 and $871 \mathrm{~cm}^{-1}$ strong infrared bands, while the ring breathing mode is associated with the very strong Raman band at $819 \mathrm{~cm}^{-1}$.

Table 2 Comparison of observed Raman and infrared bands with calculated normal modes of a glycolaldehyde dimer in the stable $\alpha$ phase at $295 \mathrm{~K}\left(\mathrm{~cm}^{-1}\right)$.

\begin{tabular}{|l|l|l|l|l|l|}
\hline Observed & Infrared & Value & $\begin{array}{l}\text { Raman Intensity } \\
\left(10^{-40} \mathrm{~m}^{4} / \mathrm{amu}\right)\end{array}$ & $\begin{array}{l}\text { Infrared } \\
\text { intensity } \\
(\mathrm{km} / \mathrm{mol})\end{array}$ & Descriptive assignment $^{\underline{\underline{ }}}$ \\
\hline Raman & & 3782 & 88.0 & 0.0 & OH stretching, sym \\
\hline $3417 \mathrm{w}, \mathrm{br}$ & $3414 \mathrm{vs,} \mathrm{vbr}$ & 3783 & 0.0 & 62.0 & OH stretching, asym \\
\hline $3002 \mathrm{vs}$ & & 3131 & 197.8 & 1.8 & CH stretching, sym \\
\hline & $3001 \mathrm{~m}$ & 3131 & 11.8 & 30.9 & CH stretching, asym \\
\hline $2974 \mathrm{vs}$ & & 3123 & 248.7 & 0.2 & CH stretching, sym \\
\hline & $2973 \mathrm{~ms}$ & 3223 & 0.7 & 57.1 & CH stretching, asym \\
\hline $2956 \mathrm{~ms}$ & & 3048 & 189.8 & 0.0 & CH stretching, sym \\
\hline & $2951 \mathrm{~m}$ & 3049 & 0.0 & 69.7 & CH stretching, asym \\
\hline $1457 \mathrm{~m}$ & & 1505 & 14.6 & 0.0 & $\mathrm{CH}_{2}$ scissoring \\
\hline & $1452 \mathrm{~m}$ & 1506 & 0.0 & 8.8 & $\mathrm{CH}_{2}$ scissoring \\
\hline & & 1430 & 13.9 & 0.0 & HCC bending, sym $^{-1}$ \\
\hline & $1435 \mathrm{~m}$ & 1423 & 0.0 & 117.7 & HCC bending, asym \\
\hline
\end{tabular}


Mohaček-Grošev, V., Prugovečki, B., Prugovečki, S., Strukan, N. (2013), "Glycolaldehyde dimer in the stable crystal phase has axial OH groups: Raman, infrared and X-ray data analysis", Journal of Molecular Structure, Vol. 1047, pp. 209-215.

\begin{tabular}{|c|c|c|c|c|c|}
\hline & $1397 \mathrm{w}$ & 1406 & 0.0 & 7.2 & HCO bending, asym \\
\hline \multirow[t]{2}{*}{$1393 \mathrm{mw}$} & & 1400 & 4.7 & 0.0 & $\begin{array}{l}\mathrm{HCO} \text { bending }+\mathrm{CH}_{2} \\
\text { wagging }\end{array}$ \\
\hline & $1363 \mathrm{~ms}$ & 1374 & 0.0 & 3.2 & $\begin{array}{l}\mathrm{HCO} \text { bending }+\mathrm{CH}_{2} \\
\text { wagging }\end{array}$ \\
\hline $1359 \mathrm{mw}, \mathrm{sh}$ & & 1359 & 4.9 & 0.0 & $\begin{array}{l}\mathrm{HCO} \text { bending }+\mathrm{CH}_{2} \\
\text { wagging }\end{array}$ \\
\hline \multicolumn{6}{|l|}{$1354 \mathrm{mw}$} \\
\hline \multicolumn{6}{|l|}{$1314 \mathrm{w}$} \\
\hline & $1295 \mathrm{~m}, \mathrm{sh}$ & 1292 & 0.0 & 16.3 & $\mathrm{CH}_{2}$ twisting \\
\hline $1275 \mathrm{~m}$ & $1239 \mathrm{mw}$ & 1287 & 10.6 & 0.0 & $\begin{array}{l}\mathrm{CH}_{2} \text { twisting }+\mathrm{HCO} \\
\text { bending }\end{array}$ \\
\hline \multicolumn{6}{|l|}{$1265 \mathrm{~m}, \mathrm{sh}$} \\
\hline \multirow[t]{4}{*}{$1237 \mathrm{w}, \mathrm{br}$} & & 1241 & 5.7 & 0.0 & $\mathrm{C}-\mathrm{OH}$ bending \\
\hline & $1270 \mathrm{~s}$ & 1237 & 0.0 & 74.3 & $\mathrm{C}-\mathrm{OH}$ bending \\
\hline & $1143 \mathrm{~s}, \mathrm{sh}$ & & & & \\
\hline & $1138 \mathrm{~s}$ & 1156 & 0.0 & 197.7 & $\mathrm{C}-\mathrm{C}+\mathrm{C}-\mathrm{O}$ stretching \\
\hline $1112 \mathrm{w}, \mathrm{sh}$ & & 1117 & 1.0 & 0.0 & $\begin{array}{l}\mathrm{C}-\mathrm{O}(\mathrm{H}) \\
\text { stretching }+\mathrm{CH}_{2} \\
\text { rocking }\end{array}$ \\
\hline $1105 \mathrm{mw}$ & $1100 \mathrm{~s}$ & 1107 & 0.0 & 164.5 & $\mathrm{CH}_{2}$ rocking \\
\hline $1080 \mathrm{w}$ & $1079 \mathrm{~ms}$ & 1088 & 3.6 & 0.0 & $\mathrm{C}-\mathrm{O}$ stretching, sym \\
\hline \multirow[t]{6}{*}{$1037 \mathrm{~m}$} & & 1050 & 9.8 & 0.0 & $\mathrm{C}-\mathrm{O}$ stretching, asym \\
\hline & $1023 \mathrm{~s}$ & 1016 & 0.0 & 268.6 & $\begin{array}{l}\mathrm{C}-\mathrm{O} \text { stretching, crystal } \\
\text { splitting }\end{array}$ \\
\hline & $1013 \mathrm{~m}, \mathrm{sh}$ & & & & \\
\hline & $960 \mathrm{vw}$ & & & & \\
\hline & $913 \mathrm{~s}$ & 908 & 0.0 & 75.4 & $\mathrm{C}-\mathrm{O}$ stretching, asym \\
\hline & $901 \mathrm{~s}$ & & & & \\
\hline $908 \mathrm{mw}$ & & 907 & 6.9 & 0.0 & $\mathrm{C}-\mathrm{O}(\mathrm{H})$ stretching, sym \\
\hline \multicolumn{6}{|l|}{$899 w$} \\
\hline & $871 \mathrm{~s}$ & 877 & 0.0 & 72.5 & C-C stretching \\
\hline \multirow{2}{*}{819 vs } & & 810 & 19.8 & 0.0 & Ring breathing \\
\hline & $812 \mathrm{~s}$ & 809 & 0.0 & 59.0 & OCC bending \\
\hline $710 \mathrm{~m}$ & & 708 & 4.7 & 0.0 & Ring bending \\
\hline $561 \mathrm{~m}$ & & 556 & 3.1 & 0.0 & $\mathrm{OCO}(\mathrm{H})$ bending, sym \\
\hline \multicolumn{6}{|l|}{$549 \mathrm{w}$} \\
\hline & $535 \mathrm{~s}$ & 540 & 0.0 & 45.3 & $\mathrm{OCO}(\mathrm{H})$ bending, asym \\
\hline & $630 \mathrm{~m}, \mathrm{sh}$ & 455 & 0.0 & 80.9 & OH torsion \\
\hline $550 \mathrm{vw}, \mathrm{br}$ & & 441 & 1.4 & 0.7 & $\mathrm{OH}$ torsion \\
\hline \multirow[t]{2}{*}{$424 \mathrm{~m}$} & $429 \mathrm{~m}$ & 424 & 1.6 & 0.0 & Ring deformation \\
\hline & $604 \mathrm{~m}$ & 423 & 92.9 & 0.0 & OH torsion \\
\hline $392 \mathrm{w}$ & & 390 & 0.7 & 0.0 & COC bending \\
\hline $266 \mathrm{w}$ & & 192 & 0.74 & 0.0 & OCC bending \\
\hline \multicolumn{6}{|l|}{$238 \mathrm{mw}$} \\
\hline & $232 \mathrm{mw}, \mathrm{br}$ & 199 & 0.0 & 21.8 & Ring deformation \\
\hline & $214 \mathrm{mw}$ & & & & \\
\hline & & 111 & 0.0 & 4.9 & Ring deformation \\
\hline
\end{tabular}

a For detailed description in terms of local symmetrized modes see Table S3. s-Strong, mmedium, w-weak, v-very, br-broad, and sh-shoulder. 
Mohaček-Grošev, V., Prugovečki, B., Prugovečki, S., Strukan, N. (2013), "Glycolaldehyde dimer in the stable crystal phase has axial OH groups: Raman, infrared and X-ray data analysis", Journal of Molecular Structure, Vol. 1047, pp. 209-215.

b Detailed potential energy distribution is given in Table S4 of the Supplementary material.
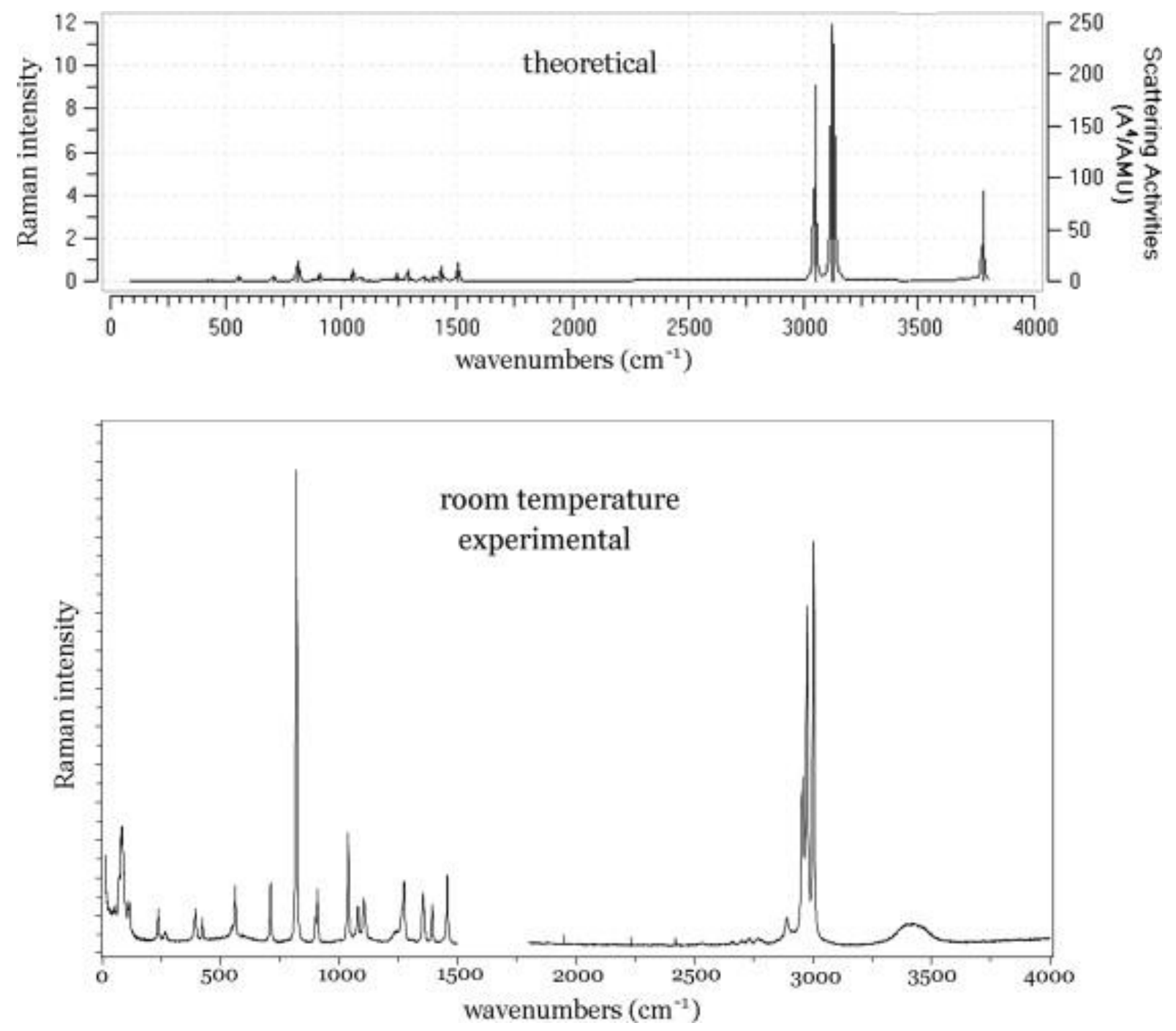

Fig 3 Comparison of the theoretical (upper) and experimental (lower) Raman spectra of glycolaldehyde powder at room temperature. 
Mohaček-Grošev, V., Prugovečki, B., Prugovečki, S., Strukan, N. (2013), "Glycolaldehyde dimer in the stable crystal phase has axial OH groups: Raman, infrared and X-ray data analysis", Journal of Molecular Structure, Vol. 1047, pp. 209-215.
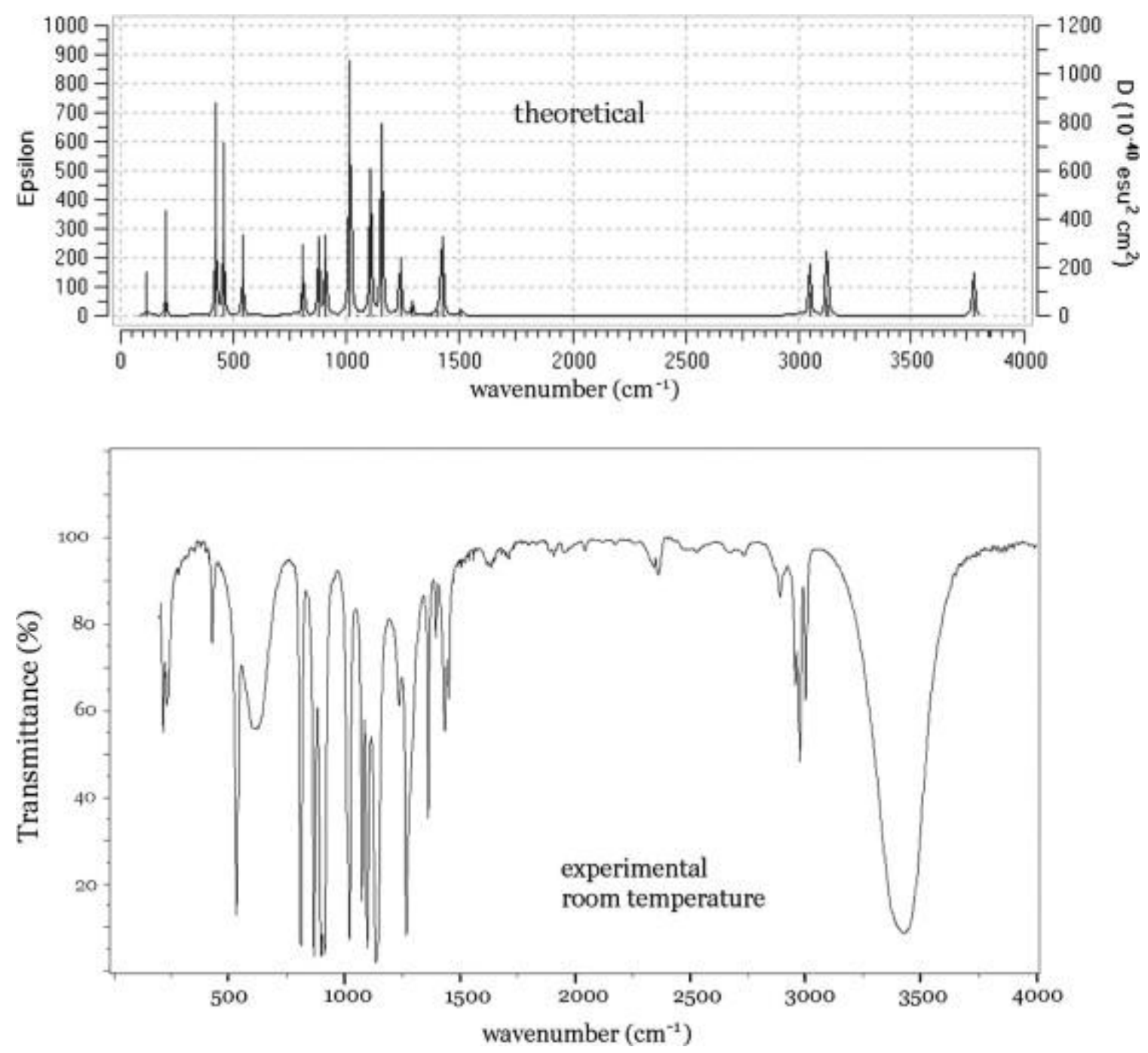

Fig 4 Comparison of the theoretical (upper) and experimental (lower) infrared spectra of glycolaldehyde powder at room temperature.

Particularly sensitive to the conformation of the hydroxyl groups are bands in the $500-650 \mathrm{~cm}^{-1}$ interval. The broad medium infrared band at $604 \mathrm{~cm}^{-1}$ having a shoulder at $630 \mathrm{~cm}^{-1}$ is one of the rare cases where crystal splitting is resolved and two bands can be assigned to the torsions of the hydroxyl groups having symmetry $A_{u}$ and $B_{u}$. Their Raman $A_{g}$ and $B_{g}$ counterparts are most probably overlapping in a very weak and broad band centered at $550 \mathrm{~cm}^{-1}$ underlying a medium $561 \mathrm{~cm}^{-1}$ and a weak $549 \mathrm{~cm}^{-1}$ band corresponding to the bending of the $\mathrm{O}-\mathrm{C}-\mathrm{O}(\mathrm{H})$ angle.

According to the normal coordinate calculation, only one internal mode is responsible for two observed Raman bands at 238 and $266 \mathrm{~cm}^{-1}$. It originates in OCC bending deformation of the 
Mohaček-Grošev, V., Prugovečki, B., Prugovečki, S., Strukan, N. (2013), "Glycolaldehyde dimer in the stable crystal phase has axial OH groups: Raman, infrared and X-ray data analysis", Journal of Molecular Structure, Vol. 1047, pp. 209-215.

ring, coupled with the bending of hydroxyl group. Similarly, two infrared bands at 214 and $232 \mathrm{~cm}^{-1}$ are chiefly due to the deformation of the $\mathrm{CO}_{\text {ring }} \mathrm{C}$ angle.

In the far infrared region, Kobayashi et al. [14] reported bands at 183, 156, 110 and $95 \mathrm{~cm}^{-1}$. Among these phonon bands, only one band is expected to be an internal vibration of the dimer.

Low temperature Raman spectra discussed in [15] exhibit an increase in the number of phonon bands from six at room temperature to thirteen at $10 \mathrm{~K}$, while the strongest band attributed to the $\mathrm{C}-\mathrm{C}$ stretching observed at $819 \mathrm{~cm}^{-1}$ splits into three bands at 812,824 and $830 \mathrm{~cm}^{-1}$ at $10 \mathrm{~K}$.

\section{Conclusion}

Glycolaldehyde dimer crystallizes in the space group $P 2_{1} / c$ with $Z=2$. Molecules are interconnected via their hydroxyl groups and oxygen atoms from the 1,4-dioxane ring, forming layers of medium strong and weak hydrogen bonds. The bands sensitive to the conformation of $\mathrm{OH}$ group are identified as the $\mathrm{C}-\mathrm{OH}$ deformations which were assigned to the IR and Raman bands at 1239 and $1237 \mathrm{~cm}^{-1}$, respectively; the two $\mathrm{O}_{1}-\mathrm{C}_{2}-\mathrm{O}_{8}$ and $\mathrm{O}_{4}-\mathrm{C}_{5}-\mathrm{O}_{12}$ deformation

modes, both associated with Raman and infrared bands at 561 and $535 \mathrm{~cm}^{-1}$, and the two torsion modes assigned to the IR bands at $630 \mathrm{~cm}^{-1}$ and $604 \mathrm{~cm}^{-1}$.

\section{Acknowledgments}

This work was supported by Croatian Ministry of Science, Technology and Sport, Grants Nos. 0980982904-2898 and 119-1193079-1084. Calculations were performed at University of Zagreb Computing Centre SRCE.

\section{Appendix A. Supplementary material}

CCDC 892871 contains the supplementary crystallographic data for glycolaldehyde dimer. These data can be obtained free of charge from The Cambridge Crystallographic Data Centre via http://www.ccdc.cam.ac.uk/data_request/cif, or from the Cambridge Crystallographic Data Centre, 12 Union Road, Cambridge CB2 1EZ, UK, fax:+44 1223 336033. Supplementary data associated with this article can be found, in the online version, at http://dx.doi.org/10.1016/i.molstruc.2013.05.006.

\section{References}

[1] J.M. Hollis, F.J. Lovas, P.R. Jewell, Astrophys. J. 540 (2000) L107-L110. 
Mohaček-Grošev, V., Prugovečki, B., Prugovečki, S., Strukan, N. (2013), "Glycolaldehyde dimer in the stable crystal phase has axial OH groups: Raman, infrared and X-ray data analysis", Journal of Molecular Structure, Vol. 1047, pp. 209-215.

[2] P. Karlson, Biokemija, Školska knjiga, Zagreb, 1988. p. 86.

[3] R.A.H. Butler, Astrophys. J. Suppl. Ser. 134 (2001) 319-321.

[4] K. Cai, J. Wang, J. Phys. Chem. B 113 (2009) 1681-1692.

[5] Y. Fan, L. Peng Leong, R.P.A. Bettens, J. Phys. Chem. A 111 (2007) 5081-5085.

[6] M.L. Senent, J. Phys. Chem. A 108 (2004) 6286-6293.

[7] G. Bouchoux, F. Penaud-Berruyer, W. Bertrand, Eur. J. Mass Spectrom. 7 (2001) 351-357.

[8] S. Ptasin’ ska, P. Limao-Vieira, S. Denifl, P. Scheier, T.D. Mark, Chem. Phys. Lett. 401 (2005) 227-231.

[9] A. Aspiala, J. Murto, P. Sten, Chem. Phys. 106 (1986) 399-412.

[10] J. Ceponkus, W. Chin, M. Chevalier, M. Broquier, A. Limongi, C. Crepin, J. Chem. Phys. 133 (2010) 094502.

[11] A. Wohl, C. Neubeg, Ber. Deutsch. Chem. Ges. 33 (1900) 3097.

[12] E. Spath, L. Raschik, Monatsh. Chem. 76 (1947) 65.

[13] H. Michelsen, P. Klaboe, J. Mol. Struct. 4 (1969) 293-302.

[14] Y. Kobayashi, H. Takahara, H. Takahashi, K. Higasi, J. Mol. Struct. 32 (1976) 235-246.

[15] V. Mohaček-Grošev, J. Raman Spectrosc. 36 (2005) 453-461.

[16] A. Boultif, D. Louer, J. Appl. Crystallogr. 37 (2004) 724.

[17] X'PertHighScorePlus Package, Panalytical B.V., Almelo, The Netherlands, 2003.

[18] A. LeBail, H. Douroy, J.L. Fourquet, Mater. Res. Bull. 23 (1988) 447.

[19] A. Altomare, M. Camalli, C. Cuocci, C. Giacovazzo, A. Moliterni, R. Rizzi, J. Appl. Cryst. 42 (2009) 1197-1202.

[20] H.M. Rietveld, J. Appl. Cryst. 2 (1969) 65-71.

[21] L.W. Finger, D.E. Cox, A.P. Jephcoat, J. Appl. Cryst. 27 (1994) 892-900.

[22] M.J. Frisch, G.W. Trucks, H.B. Schlegel, G.E. Scuseria, M.A. Robb, J.R. Cheeseman, J.A. Montgomery Jr., T. Vreven, K.N. Kudin, J.C. Burant, J.M. Millam, S.S. Iyengar, J. Tomasi, V. Barone, B. Mennucci, M. Cossi, G. Scalmani, N. Rega, G.A. Petersson, H. Nakatsuji, M. Hada, M. Ehara, K. Toyota, R. Fukuda, J. Hasegawa, M. Ishida, T. Nakajima, Y. Honda, O. Kitao, H. Nakai, M. Klene, X. Li, J.E. Knox, H.P. Hratchian, J.B. Cross, V. Bakken, C. Adamo, J. Jaramillo, R. Gomperts, R.E. Stratmann, O. Yazyev, A.J. Austin, R. Cammi, C. Pomelli, J.W. Ochterski, P.Y. Ayala, K. Morokuma, G.A. Voth, P. Salvador, J.J. Dannenberg, V.G. Zakrzewski, S. Dapprich, A.D. Daniels, M.C. Strain, O. Farkas, D.K. Malick, A.D. Rabuck, K. Raghavachari, J.B. Foresman, J.V. Ortiz, Q. Cui, A.G. Baboul, S. Clifford, J. Cioslowski, B.B. Stefanov, G. Liu, A. Liashenko, P. Piskorz, I. Komaromi, R.L. Martin, D.J. Fox, T. Keith, M.A. Al-Laham, C.Y. Peng, A. Nanayakkara, M. Challacombe, P.M.W. Gill, B. Johnson, W. Chen, M.W. Wong, C. Gonzalez, J.A. Pople, Gaussian03, Revision C.02, Gaussian, Inc., Wallingford, CT, 2004. [23] BALGA program, G. Keresztury, G. Jalszovsky, J. Mol. Struct. 10 (1971) 304.

[24] H. Rostkowska, L. Lapinski, M. Nowak, Vib. Spectrosc. 49 (2009) 43.

[25] G.K. Glushonok, T.G. Glushonok, O.I. Shadyro, Kinet. Catal. 41 (2000) 682-686. 
Mohaček-Grošev, V., Prugovečki, B., Prugovečki, S., Strukan, N. (2013), "Glycolaldehyde dimer in the stable crystal phase has axial OH groups: Raman, infrared and X-ray data analysis", Journal of Molecular Structure, Vol. 1047, pp. 209-215.

[26] M. Spiekermann, B. Schrader, A. de Meijere, W. Luttke, J. Mol. Struct. 77 (1981) 1.

[27] J.R. Durig, A. Ganguly, A.M. ElDefrawy, T.K. Gounev, G.A. Giurgis, Spectrochim. Acta A 71 (2008) 1379-1389.

[28] C. Jansen, J. Mol. Struct. THEOCHEM 398 (1977) 395-404.

[29] P.A. McGregor, D.R. Allan, C.A. Morrison, S. Parsons, L. Sawyer, Acta Cryst. B 61 (2005) 449-454.

[30] S.A. Moggach, D.R. Allan, P. Lozano-Casal, S. Parsons, J. Synchrotron Rad. 12 (2005) 590-597.

[31] E. Sciesinska, J. Mayer, I. Natkaniec, J. Sciesinski, Acta Phys. Pol. A 76 (1989) 617-629.

[32] H.A. Dabbagh, M. Naderi, A. NajafiChermahini, Carbohydr. Res. 346 (2011) 1047-1056.

[33] D. Cremer, J.A. Pople, J. Am. Chem. Soc. 97 (1975) 1354.

[34] K. S'lepokura, T. Koz' lecki, T. Lis, J. Mol. Struct. 647 (2003) 223-231.

[35] K. S'lepokura, T. Lis, Carbohydr. Res. 339 (2004) 1995-2007.

[36] A.F. Berndt, L. Barton, F. Longcor, Acta Crystallogr. C 39 (1983) 395-397.

[37] M. Senma, Z. Taira, K. Osaki, T. Taga, Chem. Commun. (1973) 880-881.

[38] P. Aped, Y. Apeloig, A. Ellencweig, B. Fuchs, I. Goldberg, M. Karni, E. Tartakovsky, J. Am. Chem. Soc. 109 (1987) 1486-1495.

[39] F.H. Allen, Acta Crystallogr. B58 (2002) 380-388.

[40] G.A. Jeffrey, An Introduction to Hydrogen Bonding, Oxford University Press, New York, Oxford, 1997. p. 12. 